\title{
STUDY OF ABNORMAL HEMOGLOBIN IN EHIME, JAPAN: TWO STRUCTURAL VARIANTS OF HEMOGLOBIN A (Hb I AND Hb J IRAN) AND STRUCTURAL AND SYNTHETIC VARIANTS OF DELTA CHAIN
}

\author{
Shuji SAITo \\ First Department of Internal Medicine, Faculty of Medicine, \\ Ehime University, Ehime 840, Japan
}

\begin{abstract}
Summary During a survey for abnormal hemoglobins in Ehime Prefecture, Shikoku, Japan, we found six cases of structural variants (one $\alpha$ chain, one $\beta$ chain and four $\delta$ chain variants) and five cases of homozygous $\delta$-thalassemia. From this, the frequency of visible structural variants detected in this survey was approximately one per 5,400 specimens. In addition, three cases with an elevation of hemoglobin $A_{2}$ and 41 cases with an elevation of hemoglobin $F$ were found. The $\alpha$ chain variant was identified as hemoglobin I ( $\alpha 16 \mathrm{Lys} \rightarrow \mathrm{Glu})$, and the $\beta$ chain variant as hemoglobin J Iran ( $\beta 77$ His $\rightarrow$ Asp). Neither of these variants has been previously found in Japanese. Of great interest in this survey was that rare $\delta$ chain abnormalities were frequently found. Four of them were $\delta$ chain structural variants and five were homozygous $\delta$-thalassemia. In addition, the $\delta$-thalassemia was associated with hereditary persistence of fetal hemoglobin (HPFH) of heterocellular type in two families but not in the other three families.
\end{abstract}

\section{INTRODUCTION}

Hemoglobin abnormalities are classic models of the diseases resulting from molecular and genetic defects. The study of abnormal hemoglobin in Japan started in 1957, and systematic survey has been focused on Western Japan. However, the result of this kind of survey has not been reported from the Island of Shikoku, Japan. To investigate the hemoglobin abnormalities in Ehime Prefecture, Shikoku, we have conducted systematic screening survey for abnormal hemoglobin. The present paper reports the results of the screening survey.

Received May 21, 1984; revised version received August 3, 1984 


\section{MATERIALS AND METHODS}

Blood specimens used for the screening survey were obtained from outpatient clinics of Ehime University Hospital, Matsuyama Red Cross Hospital and Yawatahama City Hospital in Ehime Prefecture, during the period from 1975 to 1980.

Hematological studies were carried out by standard methods. Venous blood was collected in acid citrate dextrose (ACD) solution and hemolysate was prepared by the method of Drabkin (1946). The test for thermostability of hemoglobin was performed by the method of Dacie et al. (1964). Thin-layer starch gel electrophom resis of the hemolysate was performed by the method of Yamaoka et al. (TrisEDTA-borate buffer, pH 8.6) (1972). The gels were stained for protein with Amido Black 10B (Merck) and for heme with benzidine.

Isolation of the hemoglobin was performed by chromatography on carboxymethylcellulose (CM-cellulose, CM-52: microgranular, preswollen, Whatman) using a $\mathrm{pH}$ gradient of $0.01 \mathrm{M}$ sodium phosphate buffer containing $0.01 \% \mathrm{KCN}$ (Huisman and Jonxis, 1980). Quantitative estimation of hemoglobin $A_{2}$ was performed by chromatography on diethyl-aminoethylcellulose (DEAE-cellulose, DE-52: microgranular, preswollen, Whatman) using a concentration gradient of $\mathrm{NaCl}$ containing $0.2 \mathrm{M}$ glycine and $0.01 \% \mathrm{KCN}$ (Huisman and Jonxis, 1980). The normal value for hemoglobin $\mathrm{A}_{2}$ determined by this method averaged $2.5 \%$, ranging from 1.5 to $3.4 \%$. Quantitative estimation of hemoglobin $\mathrm{F}$ was performed by the one minute denaturation method of Singer et al. (1951). The normal value for hemoglobin $\mathrm{F}$ determined by this method averaged $0.7 \%$, ranging from 0.3 to $1.0 \%$. The distribution of hemoglobin $\mathrm{F}$ in the red blood cells was assayed by the acid elution technique of Betke and Kleihauer (1958).

Globin was prepared with cold acid acetone by the method of Clegg et al. (1966). Chain separation of globin was performed by chromatography on CMcellulose (CM-52: microgranular, preswollen, Whatman) using a sodium ion gradient of phosphate buffer containing $8 \mathrm{M}$ urea and $0.05 \mathrm{M}$ 2-mercaptoethanol (Huisman and Jonxis, 1976). Aminoethylation (AE) of the globin was performed by the method of Clegg et al. (1966) and tryptic digestion (Trypsin-TCA, Worthington) of aminoethylated chain was carried out by the method of Katz et al. (1959). Separation of the tryptic digest of aminoethylated globin chain was carried out by the peptide mapping technique of Ingram (1958) using the chromatographic solvent system of Baglioni (1961), followed by high voltage electrophoresis in pyridine acetate buffer. The dried peptide map was rendered visible with $0.2 \%$ ninhydrin in acetone solution. Subsequently, peptides were eluted from the paper with $10 \%$ acetic acid and quantitative amino acid analysis of the peptides was performed with the Hitachi Model KLA 3B automatic amino acid analyzer. 


\section{RESULTS}

\section{Frequencies of structural and synthetic variants of hemoglobin}

Blood specimens were obtained from 32,569 adults who visited the Ehime University Hospital and other two hospitals in Ehime Prefecture. In the course of this screening survey for abnormal hemoglobins, we have found six structural and five synthetic hemoglobin variants: an $\alpha$ chain variant (hemoglobin I), a $\beta$ chain variant (hemoglobin J Iran) and four $\delta$ chain variants, and five homozygous $\delta$ thalassemia (Table 1).

\section{Hemoglobin I found in Matsuyama}

The proposita was a 48-year-old female who visited Matsuyama Red Cross Hospital because of muscular weakness of extremities and then was diagnosed to have polymyositis. She had no history of jaundice or hemolysis. Hematological findings were as follows: hemoglobin, $14.0 \mathrm{~g} / \mathrm{dl}$; red cell count, $4.81 \mathrm{million} / \mathrm{cmm}$; hematocrit, $43.0 \%$; color index, $0.9 ; \mathrm{MCV}, 89.4 \mathrm{ff}$ MCH, $31.0 \mathrm{pg} ; \mathrm{MCHC}, 32.6$ $\mathrm{g} / \mathrm{dl}$; reticulocyte, $0.7 \%$. Erythrocyte morphology was normal and no target cells were observed in the peripheral blood smear.

Thin-layer starch gel electrophoresis of the hemolysates from the patient revealed the presence of an abnormal hemoglobin which is detected as a fast moving component (Fig. 1). This component was separated from hemoglobin A and hemoglobin $\mathrm{A}_{2}$ by chromatography on $\mathrm{CM}$ cellulose and found to be approximately $15.0 \%$ of the total hemoglobin, while hemoglobin $\mathrm{A}$ and hemoglobin $\mathrm{A}_{2}$ were $81.5 \%$ and $3.5 \%$, respectively (Fig. 2 ). The heat denaturation test revealed no difference

Table 1. Frequencies of structural and synthetic variants of hemoglobin among 32,569 adult blood specimens.

A. Structural alteration

\begin{tabular}{clcc}
\hline Affected chain & Name of hemoglobin & $\begin{array}{c}\text { Position and } \\
\text { structural alteration }\end{array}$ & $\begin{array}{c}\text { Frequency } \\
\text { of variant }\end{array}$ \\
\hline$\alpha$ & Hemoglobin I & 16 Lys $\rightarrow$ Glu & $1 / 32,569$ \\
$\beta$ & Hemoglobin J Iran & 77 His $\rightarrow$ Asp & $1 / 32,569$ \\
$\delta$ & 4 cases & not identified & $4 / 32,569$ \\
\hline
\end{tabular}

B. Synthetic alteration

Homozygous $\delta$-thalassemia ( 5 families)

$5 / 32,569$

C. High hemoglobin $A_{2}$ and $F$

High hemoglobin $\mathrm{A}_{2}$ ( 3 cases)

$3 / 32,569$

High hemoglobin F (41 cases)

$41 / 32,569$

Vol. 29, No. 3, 1984 


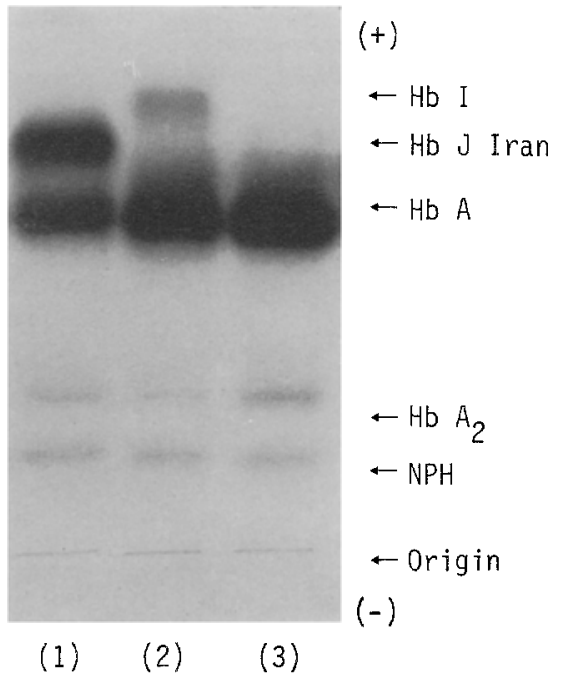

Fig. 1. Thin-layer starch gel electrophoresis at $\mathrm{pH} 8.6$ (Tris-EDTA-borate buffer) of hemolysates. (1), proposita of hemoglobin J Iran; (2), proposita of hemoglobin I; (3), normal adult. Stained with Amido Black 10B.

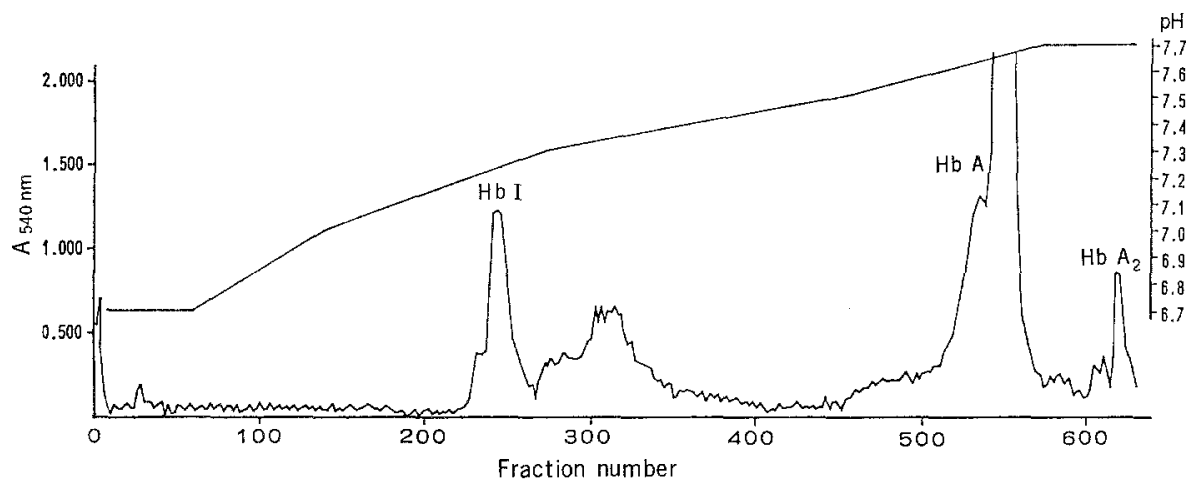

Fig. 2. Separation of hemoglobin I by chromatography on CM-cellulose using a pH gradient of $0.01 \mathrm{M}$ sodium phosphate buffer containing $0.01 \% \mathrm{KCN}$.

between this abnormal hemoglobin and hemoglobin A. Chain separation by chromatography on CM cellulose indicated that this abnormal hemoglobin was an $\alpha$ chain variant (Fig. 3). On the tryptic peptide map of the aminoethylated abnormal $\alpha$ chain, $\alpha \mathrm{Tp}-3$ and $\alpha \mathrm{Tp}-4$ (corresponding to residues 12 to 16 and 17 to 31 , respectively, of the $\alpha$ chain) were missing, and a new peptide appeared on the anodic side of $\alpha \mathrm{Tp}-4$ (Fig. 4). The amino acid analysis of this abnormal peptide indicated that this peptide contained one less lysyl residue and one more glutamyl residue than do corresponding peptides of the $\alpha$ chain, $\alpha \mathrm{Tp}-3$ and $\alpha \mathrm{Tp}-4$ (Table 2). The re- 


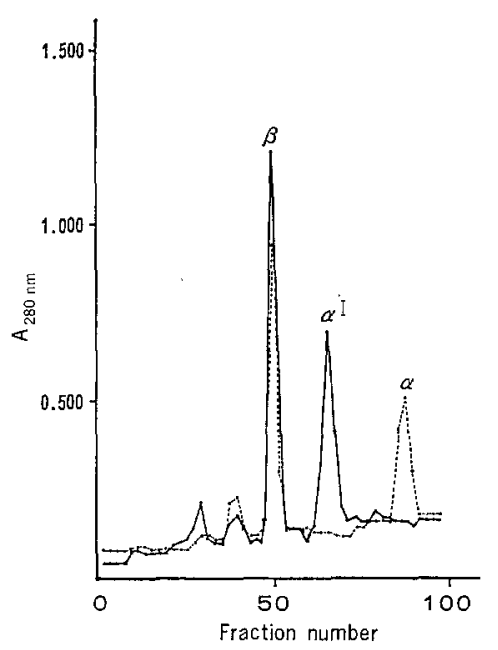

Fig. 3. Separation of globins of hemoglobin I by chromatography on CM-cellulose using a sodium ion gradient of phosphate buffer containing $8 \mathrm{M}$ urea and $0.05 \mathrm{M} \mathrm{2-}$ mercaptoethanol.

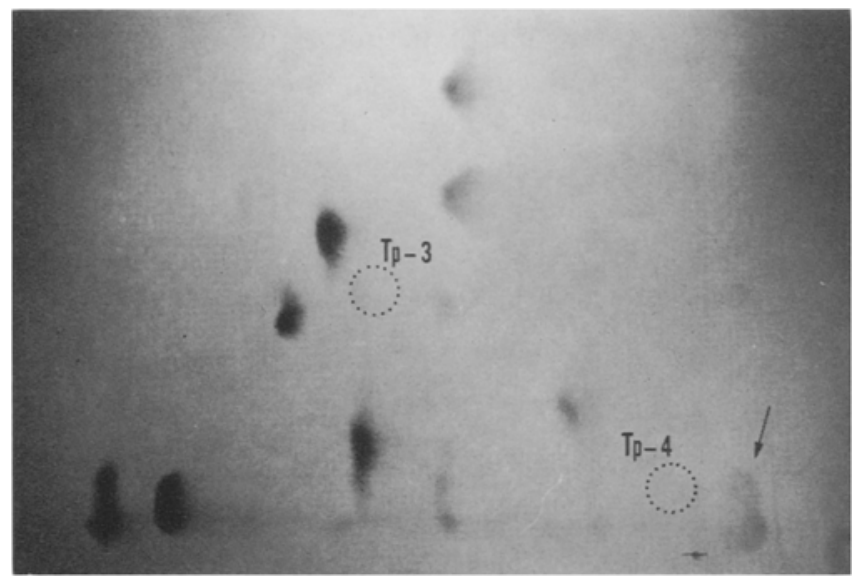

electrophoresis $(-) \longleftrightarrow(+)$

Fig. 4. Peptide map of the tryptic digest of aminoethylated abnormal $\alpha$ chain. Note the disappearance of $\alpha \mathrm{Tp}-3$ and $\alpha \mathrm{Tp}-4$ (dotted line circles). The arrow indicates the new peptide.

placement of lysine at $\alpha 16$, the C-terminus of $\alpha \mathrm{Tp}-3$, would explain the failure of tryptic cleavage at that point and the consequent linking of the two peptides, $\alpha \mathrm{Tp}-3$ and $\alpha \mathrm{Tp}-4$. Evidently, the lysine at $\alpha 16$ was replaced by a glutamyl residue, either glutamine or glutamic acid. In view of the electrophoretic mobility of this abnormal peptide and hemoglobin, the replaced residue must be an acidic amino acid and therefore the residue is glutamic acid rather than glutamine. The amino acid 
Table 2. Amino acid composition of the abnormal peptide.

\begin{tabular}{lcc}
\hline & \multicolumn{2}{c}{ Molar ratio } \\
\cline { 2 - 3 } Amino acid & $\alpha$ Tp-3 $+\alpha \mathrm{Tp}-4$ & Abnormal peptide \\
\hline Glu & 3 & $4.2(4)$ \\
Gly & 4 & $3.7(4)$ \\
Ala & 6 & $6.0(6)$ \\
Val & 1 & $1.1(1)$ \\
Leu & 1 & $1.1(1)$ \\
Thr & 1 & $0.7(1)$ \\
His & 1 & $0.9(1)$ \\
Arg & 1 & $0.9(1)$ \\
Lys & 1 & $0(0)$ \\
Try a & 1 & $+(1)$ \\
\hline
\end{tabular}

a Detected by Ehrlich reagent. A positive result was assumed to be due to one mole of tryptophan.

substitution of lysine by glutamic acid is permitted by a single base substitution in the genetic code, resulting in producing a variant hemoglobin with additional negative charge. This amino acid substitution, the replacement of lysine at $\alpha 16$ by glutamic acid, has already been reported as hemoglobin I (O'Brien et al., 1964; Beale and Lehmann, 1965; Schneider et al., 1966; Bowman and Barnett, 1967; Baur, 1968; Labossiere and Vella, 1971).

Family study could not be carried out, because no relatives of the proposita survived.

\section{Hemoglobin $J$ Iran found in Yawatahama}

The proposita was a 26-year-old female who visited Yawatahama City Hospital because of pregnancy. She was in good health and had no history of jaundice or hemolysis. Hematological findings were as follows: hemoglobin, $13.3 \mathrm{~g} / \mathrm{dl}$; red cell count, 4.22 million $/ \mathrm{cmm}$; hematocrit, $38.5 \%$; color index, $1.0 ; \mathrm{MCV}, 91.2 \mathrm{fl}$; $\mathrm{MCH}, 32.0 \mathrm{pg} ; \mathrm{MCHC}, 35.0 \mathrm{~g} / \mathrm{dl}$. Erythrocyte morphology was normal and no target cells were observed in the peripheral blood smear.

On thin-layer starch gel electrophoresis at $\mathrm{pH} 8.6$, this abnormal hemoglobin was found to be a fast moving component (Fig. 1). This component was separated from hemoglobin $\mathrm{A}$ and hemoglobin $\mathrm{A}_{2}$ by chromatography on $\mathrm{CM}$ cellulose and found to be $43.7 \%$ of the total hemoglobin, while hemoglobin $A$ and hemoglobin $\mathrm{A}_{2}$ were $53.3 \%$ and $3.5 \%$, respectively (Fig. 5). The heat denaturation test revealed no difference between this abnormal hemoglobin and hemoglobin A. Chain separation by chromatography on CM cellulose indicated that this abnormal hemoglobin was a $\beta$ chain variant (Fig. 6). On the tryptic peptide map of the aminoethylated 


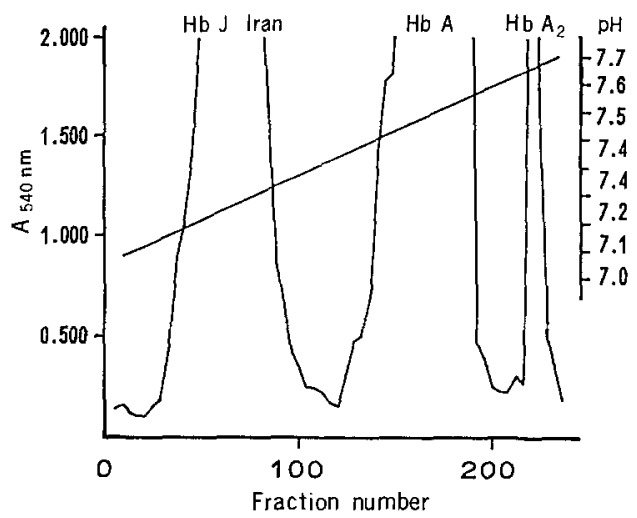

Fig. 5. Separation of hemoglobin $\mathbf{J}$ Iran by chromatography on CM-cellulose using a $\mathrm{pH}$ gradient of $0.01 \mathrm{~m}$ sodium phosphate buffer containing $0.01 \% \mathrm{KCN}$.

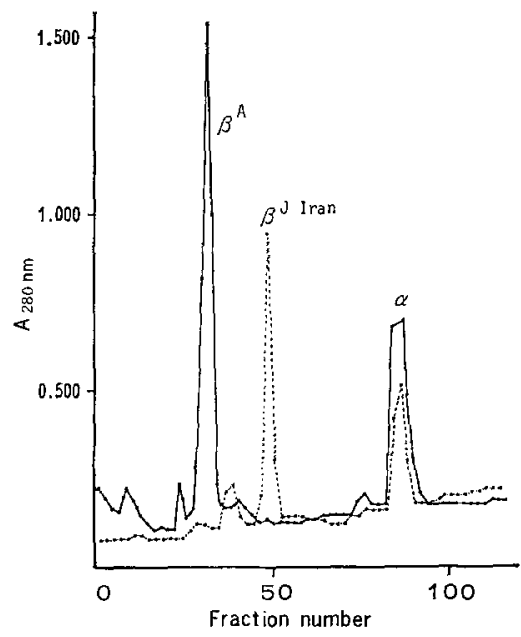

Fig. 6. Separation of globins from hemoglobin J Iran by chromatography on CM-cellulose using a sodium ion gradient of phosphate buffer containing $8 \mathrm{M}$ urea and $0.05 \mathrm{M} 2$ mercaptoethanol.

abnormal $\beta$ chain, $\beta$ Tp-9 and $\beta$ Tp- $8 \& 9$ (corresponding to residues 67 to 82 and 66 to 82 , respectively, of the $\beta$ chain) were missing, and two new peptides, peptide A and peptide B in Fig. 7, appeared on the more anodic side of $\beta$ Tp-9 and $\beta$ Tp$8 \& 9$ (Fig. 7). The amino acid analysis of peptide A revealed that this peptide was composed of one more aspartic residue compared with $\beta \mathrm{Tp}-9$, while the histidic residue seen in $\beta$ Tp-9 was missing (Table 3). This data indicated that histidine at $\beta 77$ was replaced by an aspartic residue, either aspartic acid or asparagine. In view of the electrophoretic mobility of this abnormal hemoglobin and peptide, the replaced residue must be an acidic residue and therefore the residue is aspartic acid 


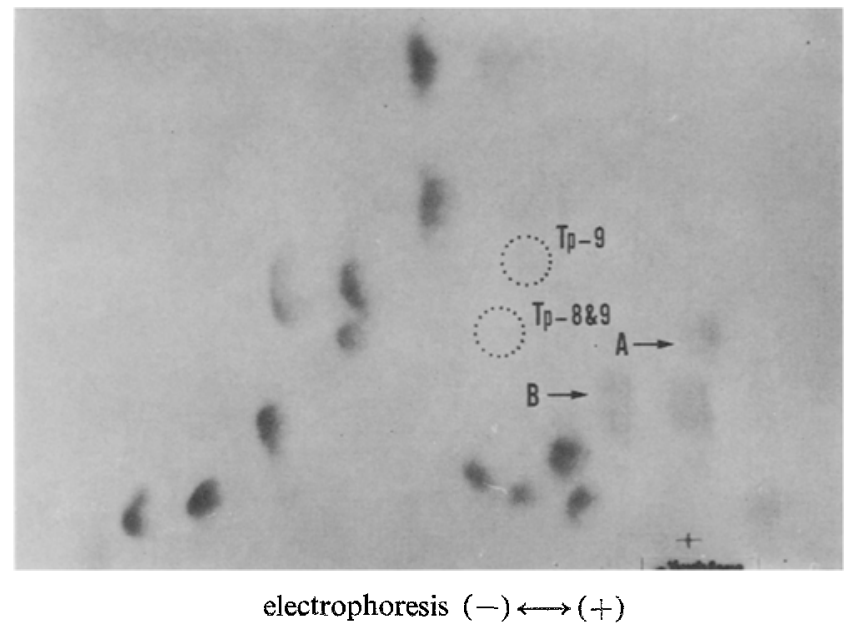

Fig. 7. Peptide map of the tryptic digest of aminoethylated abnormal $\beta$ chain. Note the disappearance of $\beta \mathrm{Tp}-9$ and $\beta \mathrm{Tp}-8 \& 9$ (dotted line circles). The arrows indicate the new peptides, peptide $A$ and peptide $B$.

Table 3. Amino acid composition of the abnormal peptide A.

\begin{tabular}{lcc} 
Amino acid & \multicolumn{2}{c}{ Molar ratio } \\
\cline { 2 - 3 } Asp & \multicolumn{1}{c}{ Abnormal peptide A } \\
Ser & 1 & $3.7(4)$ \\
Gly & 2 & $0.9(1)$ \\
Ala & 2 & $2.2(2)$ \\
Val & 1 & $1.9(2)$ \\
Leu & 4 & $0.9(1)$ \\
Phe & 1 & $4.2(4)$ \\
Lys & 1 & $1.0(1)$ \\
His & 1 & $1.0(1)$ \\
- & 1 & 0
\end{tabular}

rather asparagine. Thus histidine at $\beta 77$ was replaced by aspartic acid in this abnormal hemoglobin, and peptide A and B corresponding to $\beta$ Tp-9 and $\beta \mathrm{Tp}-8 \& 9$. The amino acid substitution of histidine by aspartic acid is permitted by a single base substitution in the genetic code, resulting in producing a variant hemoglobin with additional negative charge. This amino acid substitution, replacement of histidine at $\beta 77$ by aspartic acid, has been reported as hemoglobin J Iran (Rahbar et al., 1967).

Family study was carried out, but this abnormal hemoglobin was not detected in either the parents or the sister of the proposita. 


\section{Structural variants of $\delta$ chain}

Four cases of $\delta$ chain variants were found. Thin-layer starch gel electrophoresis of these $\delta$ chain variants are shown in Fig. 8. On thin-layer starch gel electrophoresis at $\mathrm{pH} 8.6$, the hemolysate from proband $\mathrm{Y}$ revealed an abnormal hemoglobin component migrating faster than hemoglobin $\mathrm{A}_{2}$, and the hemolysates from probands $\mathrm{K}, \mathrm{O}$ and $\mathrm{F}$ revealed abnormal components migrating slower than hemoglobin $\mathrm{A}_{2}$. Chain separation by chromatography on $\mathrm{CM}$ cellulose indicated that these abnormal hemoglobins were $\delta$ chain variants (data not shown). In family studies of these $\delta$ chain variants, electrophoretically identical abnormal hemoglobins were detected in each family members (Fig. 9). All the subjects with these $\delta$ chain variants showed no abnormal hematological findings. Chemical analysis of these $\delta$ chain variants has not been carried out yet.

\section{Homozygous $\delta$-thalassemia}

Five cases with complete absence of hemoglobin $\mathrm{A}_{2}$ were found in this survey. The pedigrees of 5 families of the probands and hematological findings of each family members are presented in Fig. 10 and Table 4.

Family $I z$. The propositus (I-1) was a 45-year-old male who was admitted for operation of gastric cancer. Hematological examinations showed mild normocytic and normochromic anemia without morphological abnormality of red blood cells. Hemoglobin $\mathrm{A}_{2}$ was absent on repeated analysis by starch gel electrophoresis and DEAE-cellulose column chromatography. He was diagnosed as homozygous $\delta$ thalassemia. The level of hemoglobin F was normal. His sons (II-1, II-2) were in good health and showed normal hematological findings. However, their hemoglo-

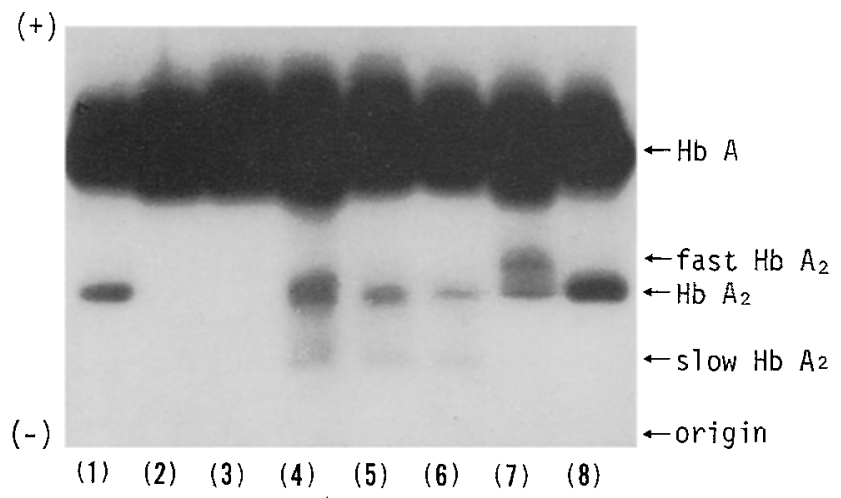

Fig. 8. Thin-layer starch gel electrophoresis at pH 8.6 (Tris-EDTA-borate buffer) of hemolysates. (1) and (8), normal adults; (2), and (3), $\delta$-thalassemia homozygotes, probands of family $\mathrm{Oz}$ and $\mathrm{Iz}$, respectively; (4), (5) and (6), slow moving $\delta$ chain variants, probands of family $\mathrm{K}, \mathrm{O}$ and $\mathrm{F}$, respectively; (7), fast moving $\delta$ chain variant, proband of family $Y$. Benzidine staining. 

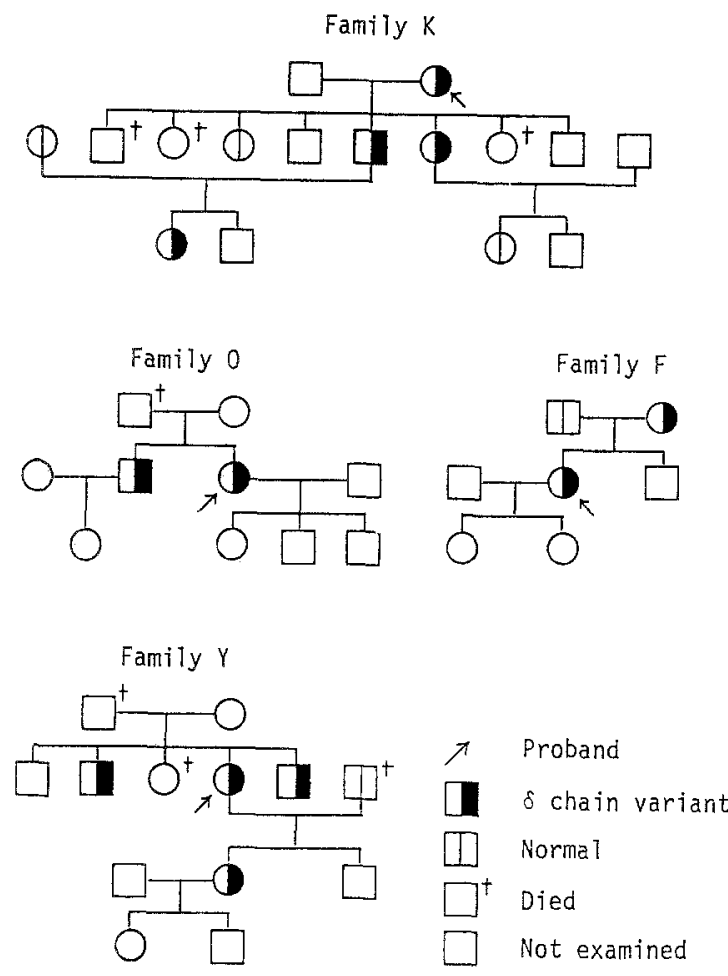

Fig. 9. Four family trees of $\delta$ chain variants.

bin $\mathrm{A}_{2}$ levels were low and the values were $1.2 \%$ and $1.3 \%$, respectively. Their hemoglobin $\mathrm{F}$ levels were normal.

Family $\mathrm{Oz}$. The propositus (II-4) was a 32-year-old male in good health and showed complete absence of hemoglobin $\mathrm{A}_{2}$. Hematological examinations showed no abnormal findings. The level of hemoglobin $F$ was normal. The parents (I-1, I-2) and four siblings (II-1, II-3, II-6, II-7) were all in good health and showed normal hematological findings. Their hemoglobin $\mathrm{A}_{2}$ levels were 1.2 to $1.4 \%$ and hemoglobin $\mathrm{F}$ levels were all within normal limits.

Family Ik. The proposita (II-2) was a 68-year-old female who had pneumonia. After recovery from pneumonia, hematological examinations showed no abnormal findings. Hemoglobin $A_{2}$ was completely absent both before and after recovery from pneumonia. The hemoglobin $F$ level was $1.1 \%$ and within normal limits. One of her siblings (II-6) and her daughter (III-1) had hemoglobin $\mathrm{A}_{2}$ levels of about one half of normal and their hemoglobin F levels were normal.

Family Ma. The proposita (II-4) was a 53-year-old female. Complete absence of hemoglobin $\mathrm{A}_{2}$ and an increase in hemoglobin $\mathrm{F}$ level were found. The level of hemoglobin $\mathrm{F}$ was elevated to $4.7 \%$. No abnormal findings were detected in the physical and hematological examinations including osmotic fragility of red blood 

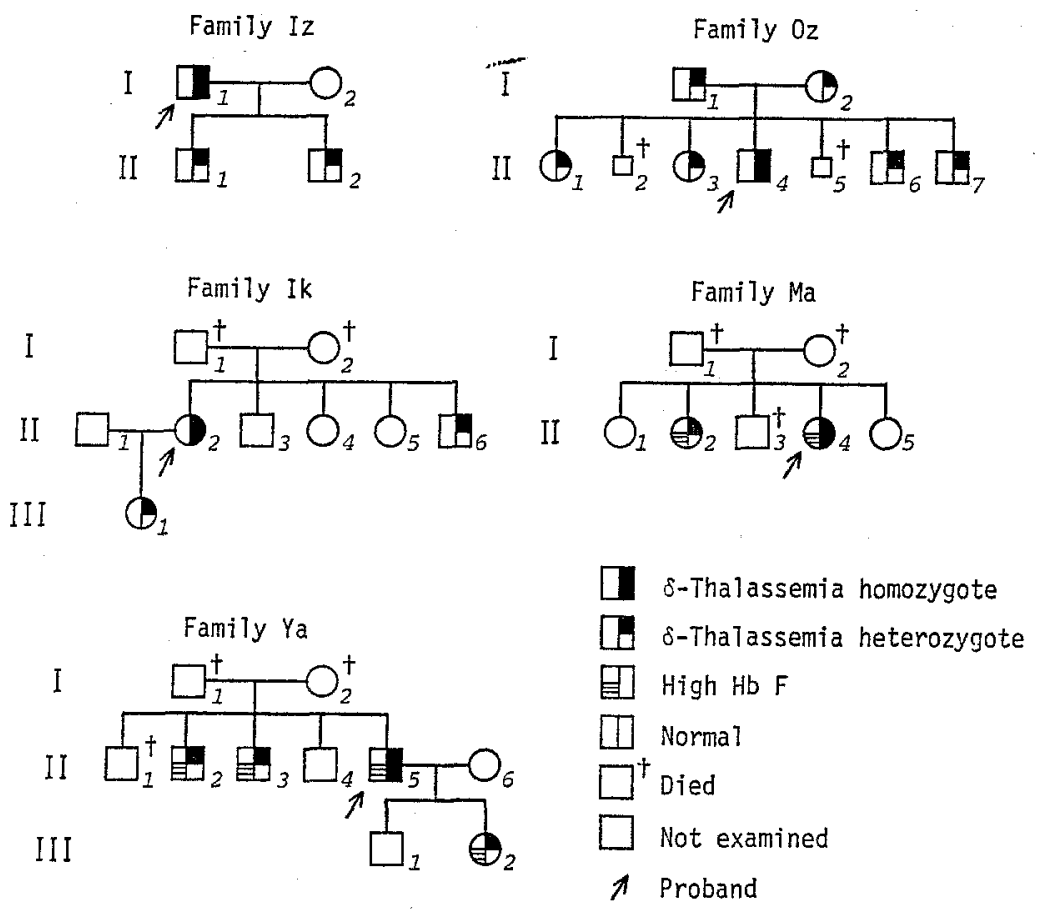

Fig. 10. Five family trees of homozygous $\delta$-thalassemia.

Table 4. Hematological findings of family members with homozygous $\delta$-thalassemia.

\begin{tabular}{|c|c|c|c|c|c|c|c|c|c|}
\hline \multicolumn{2}{|c|}{ Family \& case } & \multirow{2}{*}{$\frac{\text { Sex }}{\mathrm{M}}$} & \multirow{2}{*}{$\frac{\begin{array}{c}\mathrm{RBC} \\
\left(10^{12} / \text { liter }\right)\end{array}}{3.34}$} & \multirow{2}{*}{$\frac{\begin{array}{c}\mathrm{Hb} \\
(\mathrm{g} / \mathrm{dl})\end{array}}{10.7}$} & \multirow{2}{*}{$\begin{array}{c}\mathrm{Ht} \\
(\%)\end{array}$} & \multirow{2}{*}{$\frac{\begin{array}{l}\text { Reticulo- } \\
\text { cyte }(\%)\end{array}}{1.4}$} & \multirow{2}{*}{$\frac{\begin{array}{c}\mathrm{S}-\mathrm{Fe} \\
(\mu \mathrm{g} / \mathrm{d} l)\end{array}}{50}$} & \multirow{2}{*}{$\begin{array}{r}\frac{\mathrm{Hb} \mathrm{A_{2 }}}{(\%)} \\
0\end{array}$} & \multirow{2}{*}{$\begin{array}{c}\begin{array}{c}\mathrm{Hb} \mathrm{F} \\
(\%)\end{array} \\
0.9\end{array}$} \\
\hline$I z$ & $* \mathbf{I}-1$ & & & & & & & & \\
\hline & II-1 & M & 4.67 & 14.0 & 41 & 0.6 & n.d. & 1.2 & 0.8 \\
\hline & II-2 & $\mathbf{M}$ & 5.12 & 13.8 & 40 & 0.8 & n.d. & 1.3 & 1.0 \\
\hline \multirow[t]{7}{*}{$\mathrm{Oz}$} & $\mathrm{I}-1$ & $\mathbf{M}$ & 3.96 & 13.1 & 35 & 0.5 & n.d. & 1.2 & 0.8 \\
\hline & $\mathrm{I}-2$ & F & 3.97 & 11,1 & 35 & 0.7 & n.d. & 1.2 & 1.2 \\
\hline & II-1 & F & 4. 33 & 12.6 & 35 & 0.5 & n.d. & 1.4 & 0.9 \\
\hline & II -3 & $\mathrm{~F}$ & 4.13 & 11.7 & 32 & 0.6 & n.d. & 1.3 & 0.8 \\
\hline & *II-4 & $\mathbf{M}$ & 4.81 & 13.6 & 41 & 0.4 & 111 & 0 & 1.0 \\
\hline & II 6 & M & 4.72 & 14.2 & 40 & 0.3 & n.d. & 1.4 & 0.9 \\
\hline & II-7 & M & 5.79 & 17.5 & 47 & 0.5 & n.d. & 1.3 & 0.8 \\
\hline \multirow[t]{3}{*}{ Ik } & *II-2 & F & 4.26 & 12.5 & 35 & 1.8 & 100 & 0 & 1.1 \\
\hline & II-6 & M & 4. 15 & 12.3 & 37 & 1.0 & n.d. & 0.7 & 0.7 \\
\hline & III-1 & $\mathrm{F}$ & 5.23 & 15.2 & 45 & 1.4 & n.d. & 1.1 & 0.9 \\
\hline \multirow[t]{2}{*}{$\mathrm{Ma}$} & II-2 & F & 3.85 & 12.6 & 38 & n.d. & n.d. & 1.0 & 4. $0 \dagger$ \\
\hline & *II-4 & $\mathrm{F}$ & 4. 47 & 13.0 & 41 & 0.9 & 106 & 0 & $4.7^{\dagger}$ \\
\hline \multirow[t]{4}{*}{$\mathrm{Ya}$} & II-2 & $\mathrm{M}$ & 4.61 & 14.9 & 42 & 0.5 & n.d. & 1.0 & $3.5 t$ \\
\hline & II-3 & M & 4. 51 & 15.3 & 43 & 0.7 & n.d. & 1.1 & $3.5 t$ \\
\hline & $* I I-5$ & $M$ & 5.36 & 16.8 & 50 & 0.7 & 135 & 0 & $3.8 t$ \\
\hline & III-2 & $F$ & 4. 16 & 13.0 & 36 & 0.5 & n.d. & 1.3 & $2.8 t^{\dagger}$ \\
\hline
\end{tabular}

*Homozygous $\delta$-thalassemia. † Heterocellulary distributed. n.d.: not examined. 
cells. Her sister (II-2) was in good health and her hemoglobin $\mathrm{A}_{2}$ level was $1.0 \%$, which is about one half of the normal. Her hemoglobin $F$ was elevated to $4.0 \%$. In these cases, hemoglobin $\mathrm{F}$ was heterocellulary distributed in the red blood cells.

Family Ya. The propositus (II-5) was a 52-year-old male in good health. Complete absence of hemoglobin $\mathrm{A}_{2}$ was found and the level of hemoglobin $\mathrm{F}$ was elevated to $3.8 \%$. Physical and hematological examinations revealed no abnormalities. His two brothers (II-2, II-3) and his daughter (III-2) were all in good health. Their hemoglobin $\mathrm{A}_{2}$ levels were approximately one half of the normal and hemoglobin $\mathrm{F}$ were elevated to $2.8-3.5 \%$. In this family members, hemoglobin $\mathrm{F}$ was heterocellulary distributed in the red blood cells.

\section{High hemoglobin $A_{2}$ and $F$}

Three cases showed an elevation of hemoglobin $\mathrm{A}_{2}$ and 41 cases showed an elevation of hemoglobin $F$, but detailed analysis of these cases has not been carried out. Three cases of high hemoglobin $\mathrm{A}_{2}$ were associated with benign disorders and revealed normal hematological findings. Forty-one cases showed an elevation of hemoglobin $F$, in which seven cases were associated with a malignant or hematological disorders (two cases of uterus carcinoma, one case of acute myeloblastic leukemia, one case of Hodgkin's disease, one case of multiple myeloma, and two cases of aplastic anemia) and two cases were pregnant women in first trimester. Other thirty-two cases were associated with benign disorders.

\section{DISCUSSION}

\section{Frequencies of structural and synthetic variants of hemoglobin}

Up to the present, about 80 structural variants have been detected in Japanese. In a successive screening survey of 32,569 adult specimens, we found six structural variants of hemoglobin (one $\alpha$ chain, one $\beta$ chain and four $\delta$ chain variants) and five cases of homozygous $\delta$-thalassemia. From this, the frequency of visible structural variants detected in our screening survey may be roughly estimated to be one per 5,400 specimens, and does not vary greatly from other reported estimates using electrophoresis in Japan: one per 3,700 (Sumida, 1975); one per 3,800 (Imamura, et al., 1980); one per 3,049 (Shibata et al., 1980); one per 2,700-4,000 (Shibata, 1981); one per 5,000 (Nakatsuji et al., 1982). In this survey, the $\alpha$ chain variant found in Matsuyama was confirmed as hemoglobin $I$, and the $\beta$ chain variant found in Yawatahama was confirmed as hemoglobin J Iran. Neither of these variants had been previously found in Japanese. In addition, it is interesting that structural and synthetic variants of $\delta$ chain were found in surprisingly high incidence.

\section{Hemoglobin I}

The electrophoretically fast moving variant found in Matsuyama was proved to be an $\alpha$ chain variant. In this variant, lysine at $\alpha 16$ (A 14) was replaced by glutamic acid. This amino acid substitution has already been reported as hemo- 
globin I (O'Brien et al., 1964; Beale and Lehman, 1965; Schneider et al., 1966; Bowman and Barnett, 1967; Baur, 1968; Labossiere and Vella, 1971). In the present study, family data could not be obtained, because no relatives of the proposita survived.

Hemoglobin I has been found in individuals of various racial backgrounds, such as several black families in the USA, a black family and several Arab-Berber subjects in Algeria, several white American families, and an English subject. Nevertheless, no case had been found in Japanese. The occurrence of hemoglobin I in such different and geographically separate populations suggests that the variant is the result of independent spontaneous mutation, but precise cause of frequent occurrence of the amino acid substitution, i.e., replacement of lysine at $\alpha 16$ by glutamic acid, is not clear. As reported before, hemoglobin I caused no apparent clinical or hematological abnormalities in our case either. The amino acid substitution in hemoglobin I occurs at one of the invariant residue, but hemoglobin I had perfectly normal functional properties (McDonald et al., 1974).

\section{Hemoglobin J Iran}

Another electrophoretically fast moving variant found in Yawatahama was proved to be a $\beta$ chain variant. In this variant, histidine at $\beta 77$ (EF 1) was replaced by aspartic acid. This amino acid substitution has already been reported as hemoglobin J Iran (Rahbar et al., 1967), and up to the present no additional case has been reported. This variant hemoglobin caused no clinical and hematological abnormalities in the proposita. In a family study, this abnormal hemoglobin was not detected in the parents or the sister of the proposita. The analysis for parentage has not been carried out yet. Therefore it is not clear whether or not this variant hemoglobin was a result of a fresh mutation.

\section{Structural variants of $\delta$ chain}

Up to the present, no case of $\delta$ chain variant has been discovered in Japanese, and only ten $\delta$ chain variants have been reported in the world. In this survey, we found four cases of $\delta$ chain variants; one fast moving and three slow moving variants. In family studies of these $\delta$ chain variants, we found electrophoretically identical abnormal hemoglobins in at least one of first degree of relatives in each family. There was no genealogical relationship among these families. Structural analysis of the variant $\delta$ chains has not been carried out yet, therefore it is not clear whether or not these $\delta$ chain variants are identical to the previously reported one.

\section{Homozygous $\delta$-thalassemia}

The homozygous $\delta$-thalassemia was first reported by Ohta et al. (1971). As previously reported by us, five cases with complete absence of hemoglobin $\mathrm{A}_{2}$ were discovered and confirmed as homozygous $\delta$-thalassemia (Ohta et al., 1980; Yasukawa et al., 1980). The total of five individuals with homozygous $\delta$-thalassemia and 14 individuals with heterozygous $\delta$-thalassemia were found in five families. Almost all the subjects with homozygous and heterozygous $\delta$-thalassemia were in good health without hematological abnormalities. These findings suggest that clin- 
ical and hematological abnormalities are not necessarily associated with $\delta$-thalassemia.

In two of the five families of homozygous $\delta$-thalassemia, all the subjects with $\delta$-thalassemia also carried heterocellular hereditary persistence of fetal hemoglobins (HPFH), ranging from 2.8 to $4.7 \%$ of hemoglobin F. As reported by Ohta et al. (1971), heterocellular HPFH was also found in some members of these families. Some forms of pancellular HPFH results from the gene deletion of parts of $\gamma \delta \beta$ globin gene complex (Kan et al., 1975; Wood et al., 1977a). In 1974, Huisman et al. (1974) postulated that the preservation of hemoglobin $F$ synthesis in $\delta \beta$-thalassemia and HPFH was due to the deletions of regulatory gene sequences responsible for $\gamma$-globin gene expression. Recently, the restriction enzyme mapping technique has provided a great deal of information. The gene sequences, which lies $5^{\prime}$ side to the $\delta$-globin gene and $3^{\prime}$ side to the $\beta$-globin gene, regulate the postnatal $\delta$-globin gene suppression (Fritsch et al., 1979; Ottolenghi et al., 1979; Wood et al., 1979; Bernard and Flavell, 1980; Tuan et al., 1980; Wilson et al., 1980). Removal of inactivation of these sequences results in the postnatal persistence of hemoglobin $F$ synthesis. In pancellular HPFH the greater deletion results in loss of these regulatory gene sequences. On the other hand, little is known about the molecular genetics of heterocellular HPFH. Based on studies on the relationship between heterocellular HPFH and $\beta$-thalassemia, it has been suggested that the heterocellular HPFH determinant might be linked to $\gamma \delta \beta$-globin gene complex (Wood et al., 1976; Wood et al., 1977b). In many respects, the heterocellular HPFH are potentially a very informative group, since these cases involve subtle reciprocal changes in the expression of normal $\gamma, \delta$ and $\beta$ globin loci, without the associated massive structural deformities of the genome characteristic of most, if not all, of pancellular HPFH. The study of cases heterozygous for the Greek form of HPFH indicated that it is not associated with large gene deletions (Jones et al., 1981; Jones et al., 1982; Wood et al., 1982).

The molecular pathology of $\delta$-thalassemia has not been clarified: Thalassemia and HPFH are closely related disorders, but the relationship between $\delta$-thalassemia and heterocellular HPFH is not clear; the genetic mechanism of the decreased hemoglobin synthesis is not clear. Genetic analysis of these cases may give a clue to clarify the genetic mechanism of $\delta$-thalassemia and the control mechanism responsible for $\gamma$ chain expression.

\section{High hemoglobin $A_{2}$ and $F$}

Three cases showed an elevation of hemoglobin $\mathrm{A}_{2}$ and 41 cases showed an elevation of hemoglobin $F$. An increase in hemoglobin $A_{2}$ has been identified as syndromes associated with heterozygous state of $\beta$-thalassemia, but detailed analysis of these cases was not carried out in the present study.

An increase of hemoglobin $\mathrm{F}$ is associated with some inherited disorders, such as $\mathrm{HPFH}, \beta^{0}$-thalassemia, $\beta^{+}$-thalassemia and hemoglobin Lepore. In addition, increased amounts of hemoglobin $F$ have been described in various acquired con- 
ditions, such as pregnancy, leukeima, sideroblastic anemia, pernicious anemia, myelofibrosis, aplastic anemia, paroxysmal nocturnal hemoglobinuria and malignant diseases. In these acquired conditions, increase of hemoglobin $F$ is thought to be due to abnormal bone marrow function which is usually associated with these conditions, but no consistent pattern is seen in any of these conditions. Seven out of 41 cases with an elevation of hemoglobin $F$ were associated with hematological or malignant disorders. The other cases were found in benign disorders and high hemoglobin $\mathrm{F}$ condition was not directly related to the disorders. Howerver, there is a possibility that heterozygous $\beta$-thalassemia and HPFH might be included in these cases. Miyoshi et al. (1978) reported the high incidence of heterocellular HPFH, Tokushima type, by the method of immunofluorescence. At present, it is not clear whether or not these cases are related to "Tokushima type" of HPFH.

Acknowledgments The author wishes to express bis thanks to Prof. Yuzuru Kobayashi, Dr. Yoshiro Ohta fnd Dr. Shigeru Fujita of the First Department of Internal Medicine, Faculty of Medicine, Ehime University for their continuous support and advice. The author is also grateful to Dr. Mikio Okamura, the Ohita Red Cross Hospital, Dr. Keiichi Kuwajima, Dr. Akira Murakami and Junko Imai, the Matsuyama Red Cross Hospital, and Dr. Ryoichi Yoshida, the Yawatahama City Hospital, for their collaboration in the screening of blood samples. This work was supported by Research Grant of Ehime-Ken Hokeniryozaidan, 1977-79.

\section{REFERENCES}

Baglioni, C. 1961. An improved method for the fingerprinting of human hemoglobin. Biochim. Biophys. Acta 48: 392-396.

Baur, E.W. 1968. Hb $a_{2}$ Glu $\beta_{2}$ (Hb I) in a Caucasian family: Independent mutation or common origin? Humangenetik 6: 368-372.

Beale, D. and Lehmann, H. 1965. Abnormal haemoglobins and the genetic code. Nature 207: 259-261.

Bernard, R. and Flavell, R.A. 1980. Physical mapping of the globin gene deletion in hereditary persistence of foetal haemoglobin (HPFH). Nucl. Acids Res. 8: 1521-1534.

Betke, K. and Kleihauer, E. 1958. Fetaler und bleibender Blutfarbstoff von Erythrozyten und Erythroblasten von menschlichen Fötus und Neugeborenen. Blut 4: 241-249.

Bowman, B.H. and Barnett, D.R. 1967. Amino-acid substitution in haemoglobin I (Texas variant). Nature 214: 499.

Clegg, J.B., Naughton, M.A., and Weatherall, D.J. 1966. Abnormal human haemoglobin. Separation and characterization of the $\alpha$ and $\beta$ chains by chromatography, and the determination of two new variants, $\mathrm{Hb}$ Chesapeake and $\mathrm{Hb} \mathrm{J}$ Bangkok. J. Mol. Biol. 19: 91-108.

Dacie, J.B., Grimes, A.J., Meisler, A., Steingold, L., Hemsted, E.H., Beaven, G.H., and White, J.C. 1964. Hereditary Heinzbody anemia. A report of studies of five patients with mild anaemia. Br. J. Haematol. 10: 388-411.

Drabkin, D.L. 1946. Spectrometric studies. XIV. The crystallographic and optical properties of the hemoglobin of man in comparison with those of other species. J. Biol. Chem. 146: 703-723.

Fritsch, E.F., Lawn, R.M., and Maniatis, T. 1979. Characterization of deletions which affect the expression cf fetal globin gene in man. Nature 279: 598-603.

Huisman, T.H.J., Schroeder, W.A., Efremov, G.D., Duma, H., Mladenovski, B., Hyman, C.B., Rachmilewitz, E.A., Bouver, N., Miller, A., Brodie, A., Shelton, I.B., and Apell, G. 1974. The present status of the heterogeneity of fetal hemcglobin in $\beta$-thalassemia: An attempt to unify

Vol. 29, No. 3, 1984 
some observations in thalassemia and related conditions. Ann. N.Y. Acad. Sci. 232: 107-124.

Huisman, T.H.J. and Jonxis, J.H.P. 1976. The Hemoglobinopathies Techniques fof Identification, Marcel Dekker Inc, New York, pp. 206-209.

Huisman, T.H.J. and Jonxis, J.H.P. 1980. The Chromatography of Hemoglobin, Marcel Dekker Inc., New York, pp. 50-56, 74-85.

Imamura, T., Sugihara, T., Matsuo, T., Maruyama, T., Ohta, Y., Sumida, I., Yamaoka, K., and Yanase, T. 1980. Frequency and distribution of structural variants of hemoglobin and thalassemic states in Western Japan. Hemoglobin 4: 409-415.

Ingram, V.M. 1958. Abnormal human hemoglobin. 1. The comparison of normal human and sickle-cell haemoglobins by "fingerprinting." Biochim. Biophys. Acta 28: 539-545.

Jones, R.W., Old, J.M., Trent, R.J., Clegg, J.B., and Weatherall, D.J. 1981. Major rearrangement in human $\beta$-globin gene cluster. Nature 291: 39-44.

Jones, R.W., Old, J.M., Wood, W.G., Clegg, J.B., and Weatherall, D.J. 1982. Restriction endonuclease maps of the $\beta$-like globin gene cluster in the British and Greek forms of HPFH, and for one example of Gy $\beta+$ HPFH. Br, $J$. Haematol. 50:415-422.

Kan, Y.W., Holland, J.P., Dozy, A.M., Charache, S., and Kazasian, H.H. 1975. Deletion of the $\beta$-globin structure gene in hereditary persistence of foetal haemoglobin. Nature 258: 162-163.

Katz, A.N., Dreyer, W.J., and Anfinsen, C.B. 1959. Peptide separation by two-dimentional chromatography and electrophoresis. J. Biol. Chem. 234: 2897-2900.

Labossiere, A. and Vella, F. 1971. Hemoglobin I in a white family in Saskatoon. Clin. Biochem. 4: 104-113.

McDonald, M.J., Nobel, R.W., Sharma, V.S., and Ranney, H.M. 1974. Equilibrium and kinetic studies of hemoglobin I: A functionally silent amino acid substitution at an invariant residue. J. Mol, Biol, 89: 245-248.

Miyoshi, K., Kawai, H., Ohchi, H., Kaneko, Y., Niki, S., Iwasa, M., Takata, Y., Ohno, F., and Yamano, T. 1978. Hereditary persistence of fetal hemoglobin found in Japanese in high incidence. Jap. J. Human Genet. 23: 264-265.

Nakatsuji, T., Miwa, S., Ohba, Y., Hattori, Y., Miyaji, T., Miyata, H., and Shinohara, T. 1982. Hemoglobin screening in Tokyo using electrophoresis and isopropanol test. Acta Haematol. Jap. 45: 38-43.

O'Brien, C., Gray, M.J., and Jacobs, A.S. 1964. A survey of cord bloods for abnormal hemoglobin with further observations on hemoglobin I Burlington. Am. J. Obst. and Gyne. 88: 816-822.

Ohta, Y., Yamaoka, K., Sumida, I., Fujita, S., Fujimura, T., and Yanase, T. 1971. Homozygous delta-thalassemia first discovered in Japanese family with hereditary persistence of fetal hemoglobin. Blood 37: 706-715.

Ohta, Y., Yasukawa, M., Saito, S., Fujita, S., and Kobayashi, Y. 1980. Homozygous delta thalassemia in Japan. Hemogiobin 4: 417-425.

Ottolenghi, S., Giglioni, B., Comi, P., Gianni, A.M., Polli, E., Acquaye, C.T.A., Oldham, J.H., and Masera, G. 1979. Globin gene deletion in HPFH $\delta^{\circ} \beta^{0}$ thalassemia and Hb Lepore disease. Nature 278: 654-657.

Rahbar, S., BeaIe, D., Issacs; W.A., and Lehmann, H. 1967. Abnormal haemoglobin in Iran. Observation of a new variant hemoglobin $\mathrm{J}$ Iran $\left(\alpha_{2} \beta_{2} 77 \mathrm{His} \rightarrow\right.$ Asp $)$. Brit. Med. J. 1: 674-677.

Schneider, R.G., Alperin, J.B., Beale, D., and Lehmann, H. 1966. Hemoglobin I in a American Negro family: Structural and hematological studies. J. Lab. Clin. Med. 68: 940-946.

Shibata, S., Miyaji, T., and Ohba, Y. 1980. Abnormal hemoglobins in Japan. Hemoglobin 4: 395-408.

Shibata, S. 1981. Hemoglobinopathies in Japan. Hemoglobin 5: 509-515.

Singer, K., Chernoff, A.I., and Singer, L. 1951. Studies on abnormal hemoglobin. I. Their demonstration in sickle cell anemia and other hematologic disorders by means of alkali denaturation. Blood 6: 413-428.

Sumida, I. 1975. Studies of abnormal hemoglobins in Western Japan: Frequency of visible hemo- 
globin variant and chemical characterization of hemoglobin Sawara $\left(a_{2} 6 \mathrm{Ala} \beta_{2}\right)$ and hemoglobin Mugino (Hb L Ferrara: $\alpha_{2} 47 \mathrm{Gly} \beta_{2}$ ). Jap. J. Human Genet. 19: 343-363.

Tuan, D., Murnane, M.J., de Riel, J.K., and Forget, B.G. 1980. Heterogeneity in the molecular basis of hereditary persistence of fetal hemoglobin. Nature 285: 335-337.

Wilson, L.B., Huisman, T.H.J., and Wilson, J.T. 1980. Gene structure in hereditary persistence of fetal hemoglobin individuals. Hemoglobin 4: 509-514.

Wood, W.G., Weatherall, D.L., and Clegg, J.B. 1976. Interaction of heterocellular hereditary persistence of fetal haemoglobin with $\beta$-thalassemia and sickle cell anaemia. Nature 264: 247-249.

Wood, W.G., Clegg, J.B., and Weatherall, D.J. 1977a. Developmental biology of human haemoglobin. Prog. Hematol. 10: 43-90.

Wood, W.G., Weatherall, D.J., Clegg, J.B., Hamblin, T.J., Edward, J.H., and Barlow, A.M. 1977b. Heterocellular hereditary persistence of fetal haemoglobin (Heterocellular HPFH) and its interaction with $\beta$-thalassemia. Br. J. Haemat. 36: 461-473.

Wood, W.G., Clegg, J.B., and Weatherall, D.J. 1979. Hereditary persistence of fetal haemoglobin (HPFH) and $\delta \beta$ thalassemia. Br. J. Haemat. 43: 509-520.

Wood, W.G., MavRae, I.A., Darbre, P.D., Clegg, J.B., and Weatherall, D.J. 1982. The British type of nondeletion HPFH: Characterization of developmental changes in vivo and erythroid growth in vitro. Br. I. Haemat. 50: 401-414.

Yamaoka, K., Ohta, Y., and Seita, M. 1972. Thin-layer starch gel electrophoresis. Jpn. J. Hematol. 13: 800-804.

Yasukawa, M., Saito, S., Fujita, S., Ohta, Y., Ikeda, K., Matsumoto, I., and Kobayashi, Y. 1980. Five families with homozygous $\delta$-thalassemia in Japan. Br. J. Haemat. 46: 199-206. 